\title{
Modeling the stakeholder value and stakeholder risks
}

\author{
Alexander Zlygostev*, and Elena Makarova \\ Ural State University of Economics, 8 March str., 62, 620144 Ekaterinburg, Russia
}

\begin{abstract}
The aim of the paper is to expand understanding of stakeholder value and consider possibilities of its assessing for minimizing stakeholder risks. The study makes contributions to achieving a balance between interests of stakeholders and implementation of sustainable business development principles. The paper introduces a practical toolkit for modeling stakeholder value and stakeholder risks. New methods, developed by the authors to model and analyze stakeholder value and risks, determine the novelty of the study. The paper provides the results of new methodology validation performed with the use of mathematical and econometric methods applied to open source data. Models of contributions and benefits of stakeholders are examined, levels of the "gap" between contributions and benefits by groups of stakeholders are outlined, the map of "stakeholder risks" is presented. The analysis of the results allows to make conclusions and provide recommendations on establishing balanced relationships with stakeholders and minimizing stakeholder risks in order to harmonize interests for sustainable business development.
\end{abstract}

\section{Introduction}

The relevance of the study is determined by the demand for a new paradigm of corporate governance, central to which is the concept of stakeholder value. Being the focus of controversy, modern capitalism and issues related to its development, need to be reviewed. According to most economists, including World Economic Forum Founder and Executive Chairman Klaus Schwab, shareholder capitalism needs reforming and must be replaced by "stakeholder capitalism" ("conscious capitalism"). Coronavirus pandemic, environmental and social issues contribute to exacerbating of existing contradictions, and, as a result, enhance theoretical and practical relevance of the research topic.

Despite being central in many studies, the concept of "stakeholder value" remains a subject of discussion, as most theoretical formulations lack recommendations for practical implementation of stakeholder approach. This paper attempts to contribute to the development of practical tools for assessing and modeling stakeholder value.

There is a large volume of published foreign theoretical studies and literature reviews on the concept of "stakeholder value" [1,2]: R. K. Mitchell and his co-authors highlight the need of developing an interdisciplinary theory, comprising the theory of entrepreneurship,

\footnotetext{
* Corresponding author: letrus.alex@gmail.com
} 
accounting, risks, and corporate governance to create new accountability which takes into account stakeholder value based on sharing of risks by stakeholders [3]. A recent study by R. Tapaninaho, who provided an overview of "stakeholder value" narratives, introduced classification of modern approaches to the study of stakeholder value [4]. Previous study related to the current research area [5], which discusses and analyses literature on the concept of "stakeholder value", was based on the classification mentioned above.

A number of studies, conducted by I. N. Tkachenko and other authors, address the concept of stakeholder value from practical implementation perspective [6, 7].

A. B. Ankundinov considers the possibilities of assessing stakeholder value creation and distribution [8]. The study reports that research in this area should be conducted within the framework of assessment of the company's interaction with individual groups of stakeholders; however, A. B. Ankundinov predicts difficulties in applying econometric analysis in this context.

I. V. Ivashkovskaya argues that economic indicators of stakeholder value creation and the company's growth sustainability index allow to assess corporate strategies based on value creation for stakeholders [9].

The interdisciplinarity of the present study is based on theoretical and methodological foundations of modern management, economic theory, main concepts of corporate finance, enterprise economy, economic and mathematical modeling.

The paper first attempts to develop innovation and unique toolkit for managing organization's relationship with stakeholders on the bases of minimizing stakeholder risks through achieving a balance of interests (contribution and benefits of stakeholders).

The purpose of the study is to provide suggestions to develop organizational and methodological support for the effectiveness of corporate governance based on modeling the contribution and benefits of stakeholders and minimizing stakeholder risks.

The paper provides the results of new methodology validation performed with the use of mathematical and econometric methods applied to business object's open source data.

The findings add substantially to understanding the concept of stakeholders in corporate governance. Implementation the authors' methodological approach and toolkit allows to increase efficiency and quality of assessing stakeholder value on the basis of stakeholder contribution/benefit model, minimizing stakeholder risks and developing recommendations for balanced management interests of stakeholders.

\section{Materials and methods}

To diagnose stakeholder risks, "gap" analysis of stakeholders' contribution and benefits was performed. To carry out the task efficiently, models of contributions and benefits of stakeholders were designed. Modeling stakeholder value, conducted by the author, had been presented previously [10]. Mathematical and econometric methods were applied to design and construct stakeholder value models. Revenue served as a proxy for stakeholder value.

Data for modeling was obtained from open web-based sources, company sites, and informational and analytical reports (2008-2019). The constructed models allow to represent imbalances in the structure of the stakeholder values' creation and distribution, identify the "tension" and risks in stakeholder relationship. The results of the study have numerous important implications which can be recommended to object companies for minimizing stakeholder risks and achieving a balance of stakeholders' interests in order to ensure longterm sustainable development.

To achieve the purpose of the study the following research methods were used:

1. Identification and segmentation of stakeholder groups, as well as justification of their segmentation (to simplify, we address "classic" division of stakeholders' groups, such as "employees", "owners", "customers" and the others). 
2. Collecting and analyzing information presented in object company reports (open joint stock company "Zhirovoy Combinat" ("Fat Processing Plant").

3. Correlating collected data with categories of "benefits" and "contributions" of stakeholders.

4. Modeling and calculating missing information (the missing information implies "contributions" of employees and suppliers, which were calculated on the basis of econometric model. The factor multiplied by regression coefficient gives a contribution to stakeholder value, see below for more details).

5. Substitution of the obtained data into the model, calculation of "gaps", visualization of stakeholder risks

6. Providing guidance and recommendations on adjusting the distribution of contributions and benefits to achieve a balance of interests and sustainability of stakeholders' collaboration, optimization of stakeholder risks, improving a stakeholder relations policy, searching for ways to harmonize interests and relationships in the network of stakeholders.

\section{Results and discussion}

Table 1 shows a model, illustrating the dependence of revenue (proxy indicator of stakeholder value) on the indicators of employees and suppliers' benefits (remuneration and payment to suppliers). The model was designed on the basis of econometric modeling of employees and suppliers' contribution. We assumed that contribution of these categories of stakeholders is proportional to their benefits. To identify the effect, which ratio of all these factors has on revenue, a cross factor ( $m$ _to_labor: $m_{-}$to_suppliers) was introduced.

Table 1. Econometric model of stakeholder contribution

\begin{tabular}{|c|c|c|c|c|c|}
\hline Formula & \multicolumn{5}{|c|}{ 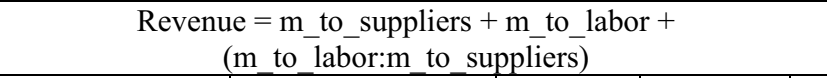 } \\
\hline Coefficients: & Estimate & Std. Error & t value & $\operatorname{Pr}(>|t|)$ & \\
\hline (Intercept) & $1,420,000.00$ & $623,800.00$ & 2.28 & 0.05 & . \\
\hline m_to_labor & 2.53 & 1.12 & 2.25 & 0.05 & . \\
\hline m_to_suppliers & 0.58 & 0.18 & 3.33 & 0.01 & $*$ \\
\hline m_to_labor:m_to_supplie & 0.0000002026 & 0.0000000663 & 3.05 & 0.02 & $*$ \\
\hline \multicolumn{6}{|c|}{ Residual standard error: 570900 on 8 degrees of freedom } \\
\hline \multicolumn{6}{|c|}{ Adjusted R-squared: 0.9969 ; F-statistic: 1162 on 3 and $8 \mathrm{DF}$, p-value $<0.000$} \\
\hline Confidence interval & \multicolumn{2}{|c|}{$2.50 \%$} & \multicolumn{3}{|c|}{$97.50 \%$} \\
\hline (Intercept) & \multicolumn{2}{|c|}{$-18,283.270$} & \multicolumn{3}{|c|}{$2,858,671.000$} \\
\hline m_to_labor & \multicolumn{2}{|c|}{-0.059} & \multicolumn{3}{|c|}{5.125} \\
\hline m_to_suppliers & \multicolumn{2}{|c|}{0.180} & \multicolumn{3}{|c|}{0.989} \\
\hline m_to_labor:m_to_supplie & \multicolumn{2}{|c|}{0.0000000496} & \multicolumn{3}{|c|}{0.0000003555} \\
\hline
\end{tabular}

The model assessment was based on the following: F-statistic $<0.05$ (number of observations are sufficient), there is a close linkage between the indicators. The indicators, which were chosen by intuition as they seemed interconnected, account for the high value of the adjusted coefficient of determination - 0.997. Moreover, this coefficient is over grading, since the analysis for multicollinearity showed correlation between the factors. This led to instability of parameter estimation. Anyway, for the purpose of the analysis under the conditions of insufficient information the model was adopted. The Durbin-Watson test showed the absence of residuals autocorrelation. 
Analysis of the collected data and application of the model allowed to calculate values of stakeholders' contribution and benefits and gaps between them (Table 2).

Table 2. Contributions, benefits, stakeholder gaps

\begin{tabular}{|c|c|c|c|}
\hline \multicolumn{4}{|c|}{ Stakeholder contribution, RUB } \\
\hline $\begin{array}{l}\text { Stakeholder } \\
\text { group }\end{array}$ & Defined by & 2019 & 2018 \\
\hline Owners & $\begin{array}{l}\text { Present amortized cost of authorized capital + } \\
\text { owners' contributions to capital in the current } \\
\text { period }\end{array}$ & 204,850 & 809,580 \\
\hline Employees & $2.53 *$ Remuneration (econometric model) & $5,210,414$ & $2,212,672$ \\
\hline Suppliers & $\begin{array}{l}0.58 * \text { Payments to suppliers } \\
\text { (econometric model) }\end{array}$ & $20,130,544$ & $6,311,163$ \\
\hline Government & no data & 0 & 0 \\
\hline Investors & $\begin{array}{l}\text { (short-term and long-term debt) } \\
\text { Risk-free rate (e.g. weighted average interest } \\
\text { rate of CBR) }\end{array}$ & 163,399 & 201,366 \\
\hline \multicolumn{4}{|c|}{ Stakeholder benefits, RUB } \\
\hline Owners & $\begin{array}{c}\text { Dividends }+ \text { increase in market value of } \\
\text { shares }\end{array}$ & 0 & $1,545,100$ \\
\hline Employees & Salary & $2,057,013$ & 873,538 \\
\hline Suppliers & Payments to suppliers & $34,434,731$ & $10,795,694$ \\
\hline Government & Tax & 90,680 & 114,311 \\
\hline Investors & Interest paid & 101,882 & 95,785 \\
\hline \multicolumn{4}{|c|}{ Gaps (Contribution - Benefits), RUB } \\
\hline Owners & & 204,850 & $-735,520$ \\
\hline Workers & & $3,153,401$ & $1,339,134$ \\
\hline Suppliers & & $-14,304,187$ & $-4,484,531$ \\
\hline Government & & $-90,680$ & $-114,311$ \\
\hline Investors & & 61,517 & 105,581 \\
\hline
\end{tabular}

The graph showing "stakeholder risks" is based on the data presented in Table 2. The "gap" is determined as the difference between contribution and benefits of stakeholders for each group and is plotted along the vertical axis of the graph (Fig. 1). Positive gap values indicate that the group of stakeholders contributes more to value creation (revenue) in comparison to what they receive in the form of benefits (wages), having the status of "donors" (employees, in our case).

The analysis of the graph proves the dominant role of suppliers and workers in creating value (abstracting from stakeholders as clients). The business of the object company is most dependent on stakeholders as suppliers. Moreover, the "suppliers" receive significantly more benefits than they invest in creating value, while the benefits of "employees", according to the model, on the contrary, are less than their contribution: this is clearly seen from their position in the positive zone of the vertical axis. Further research should concentrate on analyzing the possibility of increasing benefits of the "employees" group by temporarily halting the growth of the benefits of the group of "suppliers". This will contribute to achieving a balance of interests and minimizing stakeholder risks. 


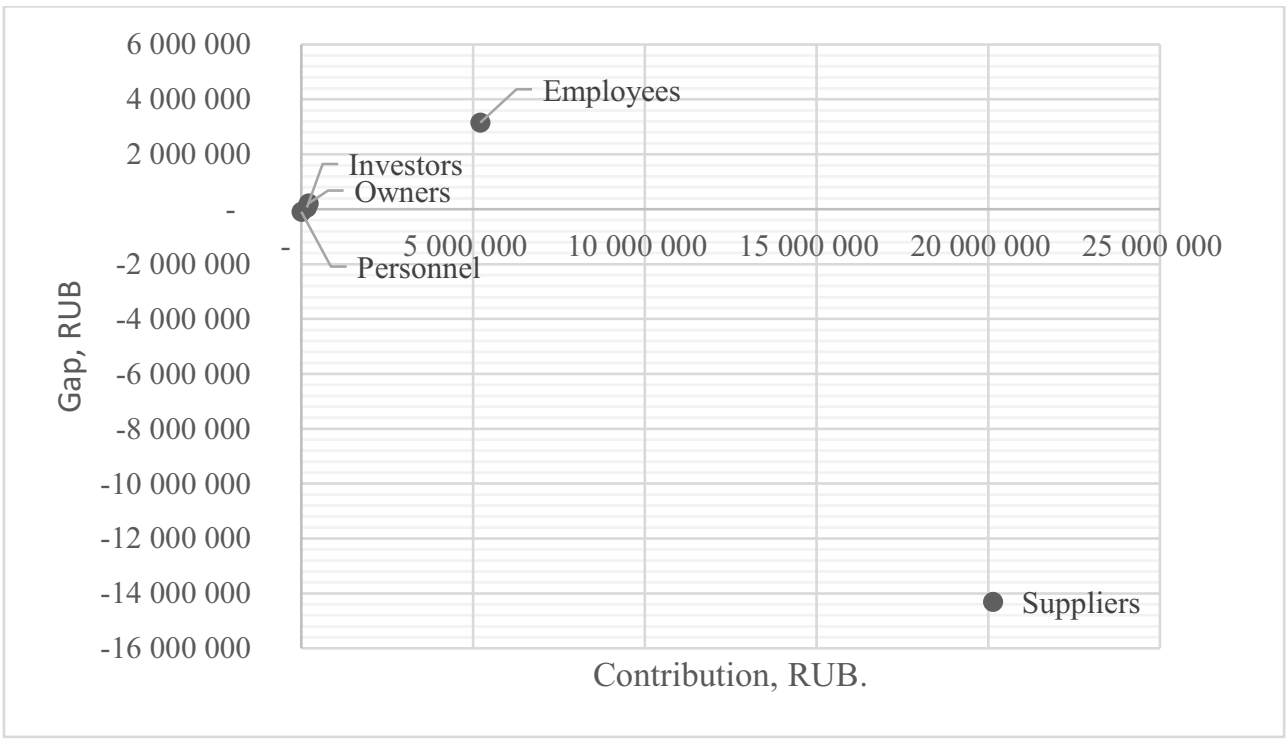

Fig. 1. Stakeholder risks map (Contribution and benefit gap map), 2019.

\section{Conclusion}

The purpose of the present study was to consider and identify stakeholder interests and risks on the basis of the designed monetary "objective" model of stakeholders' contributions and benefits and a "gap" map (stakeholder risk map). Analysis of contribution to the revenue allowed to identify categories of stakeholders.

Modeling contributions and benefits of stakeholders is significant for assessing possible stakeholder risks and damage (by assessment of the contribution of a stakeholders' group). Risk probability depends on a number of factors, including the gap between contributions and benefits of stakeholders. Applying sociological methods (polls, questionnaires, focus groups) to subjective stakeholders' assessments can help gain better understanding of the process of assessing risks' probability and specifics of risks in comparison to modeling the gap between monetary contribution and benefits.

The paper introduces a new method of assessing contributions and benefits of stakeholders in order to identify stakeholders' groups and imbalances in created and distributed value. The analysis toolkit, presented in the paper, will assist in minimizing stakeholder risks (gap level) and will contribute to harmonious and long-term development of the company's stakeholder network by achieving a balance of stakeholder interests.

\section{Acknowledgements}

The reported study was funded by RFBR and Sverdlovsk oblast, project number 20-410660032 p_a.

\section{References}

1. F. Figge, S. Schaltegger, What is stakeholder value? Developing a catchphrase into a benchmarking tool (2000)

2. E. Garriga, A. Werner, AOM Proc., 1, 17201 (2018) 
3. K.R. Mitchell, H.J. Van Buren III, M. Greenwood, R.E. Freeman, JOMS, 52, 851 (2015)

4. R. Tapaninaho, J. Kujala, Social responsibility and sustainability (2019)

5. A.A. Zlygostev, Theoretical Economics, 8 (2020)

6. I.N. Tkachenko, New trends in the development of corporate governance and business, 93 (2017)

7. I.N. Tkachenko, Institutions and values in the system of corporate relations, Effective development models (2000)

8. A.B. Ankudinov, KFU Bul., 3, 70 (2011)

9. I.V. Ivashkovskaya, Integrated management system of the company's value (2010)

10. I.N. Tkachenko, I. V. Pervukhina, A. A. Zlygostev, The Manager, 2, 2 (2020) 